\title{
A PRODUÇÃO DO DIREITO POR MEIO DE UM ESPAÇO DE TODOS E PARA TODOS: O DIREITO À SAÚDE DA POPULAÇÃO MIGRANTE
}

THE PRODUCTION OF LAW THROUGH A SPACE FOR EVERYONE: THE RIGHT TO HEALTH OF THE MIGRANT POPULATION

LA PRODUCCIÓN DEL DERECHO A TRAVÉS DE UN ESPACIO DE TODOS Y PARA TODOS: EL DERECHO A LA SALUD DE LA POBLACIÓN MIGRANTE

\section{Sandra Regina Martini ${ }^{1}$}

Licença CC BY:

Artigo distribuído sob os termos Creative Commons, permite uso e distribuição irrestrita em qualquer meio desde que o autor credite a fonte original.

\section{Janaína Machado Sturza²}

Resumo: As fronteiras servem para separar e para dividir; todavia, na sociedade cosmopolita, é preciso pensar na unificação, pois os fenômenos sociais, como a migração, requerem a superação destes limites. Assim, este artigo tem como objetivo fomentar a interlocução entre o direito à saúde e a necessidade de ultrapassar-se fronteiras, em especial as não visíveis, sob o aspecto pontual do direito à saúde do migrante. Por meio de um estudo bibliográfico, tendo como método de abordagem o hipotético-dedutivo, a reflexão proposta será norteada pela metateoria do direito fraterno, demonstrando-se, por meio dela, a possibilidade de romper barreiras sem a criação de novas, especialmente na perspectiva da produção de direitos.

Palavras-chave: Direito à Saúde; Direito Fraterno; Fronteiras; Migrantes.

Abstract:Boundariesservetoseparate and divide; However, in cosmopolitan society, we must think of unification, since social phenomena - such as migration - require overcoming these limits. The purpose of this article is to foster the interlocution between the right to health and the need to cross borders, especially invisible ones, under the specific aspect of migrants'

1 Professora Produtividade CNPq, Pós-doutora em Direito (Univerisità Roma Tre), Pós -Doutora em Políticas Públicas (Università Salerno), Doutora em Direito (Università do Salento). Professora Visitante no PPGDIR/UFRGS e Professora no Mestrado em Direitos Humanos da Universidade Ritter dos Reis - UNIRITTER. Porto Alegre/RS - Brasil. E-mail: srmvial@terra.com.br.

2 Doutora em Direito (Univerisità Roma Tre), Mestre em Direito (UNISC) e Especialista em Demandas Sociais e Políticas Públicas (UNISC). Professora na graduação em Direito da Faculdade Dom Alberto. Professora na graduação em Direito e no Mestrado em Direitos Humanos da Universidade Regional do Noroeste do Estado do Rio Grande do Sul - UNIJUI. ljuí/RS - Brasil. E-mail: janasturza@hotmail.com. 
right to health. Through a bibliographical study, taking as hypothetic-deductive approach, the proposed reflection will be guided by the metatheory of fraternal law, demonstrating, through this, the possibility of breaking barriers without creating new ones, especially from the perspective of producing Rights.

Keywords: Right to Health; Fraternal Right; Borders; Migrants.

Resumen: Las fronteras sirven para separar y para dividir; aunque, en la sociedad cosmopolita, es necesario pensar en la unificación, pues los fenómenos sociales, como la migración, requieren la superación de estos límites. De esta manera, este artículo tiene como objetivo fomentar la interlocución entre el derecho a la salud y la necesidad de ultrapasar fronteras, en especial a las no visibles, bajo el aspecto puntual del derecho a la salud del migrante. Por medio de un estudio bibliográfico, teniendo como método de abordaje el hipotético deductivo, la propuesta será norteada por la metateoría del derecho fraterno, se demostró, por medio de ella, la posibilidad de romper barreras sin la creación de nuevas, especialmente en la perspectiva de la producción de derechos.

Palabras-clave: Derecho a la Salud; Derecho Fraterno; Fronteras; Migrantes.

\section{INTRODUÇÃO}

A necessidade de alargar o nosso território com o olhar sobre o próprio território nos permite ver que é possível superar fronteiras sem criar novas fronteiras. Este é o grande desafio dos dias atuais: a superação de confins que discriminam, que excluem os tradicionalmentee os novos excluídos. Vera sociedade como planeta implica assumir uma nova postura diante da complexidade social e a possibilidade da efetivação do necessário processo de transformação social. Propomos o resgate do conceito de fraternidade e sua relação com o direito à saúde como forma de superar o egoísmo vigente nesta sociedade cosmopolita, na qual a possibilidade de transformação social é concreta, assim como são concretos os desafios para a construção de uma sociedade fundada no respeito ao outro como um outro EU.

Neste artigo, temos como foco a relação do direito à saúde com a contínua e indispensável necessidade de ultrapassar fronteiras, especialmente as fronteiras não visíveis. Por isso, fundaremos nossa reflexão na metateoria do direito fraterno, pois por meio dela podemos ver que é possível romper barreiras sem criar novas. Assim, apresentaremos o texto subdividido em tópicos: iniciaremos questionando a construção de fronteiras, mesmo sabendo que só existem duas Nações; a seguir trataremos da população migrante e seu direito ao direito à saúde; no ponto 
seguinte trataremos de mostrar como o direito à saúde pode ultrapassar barreiras na sociedade cosmopolita, para isso utilizaremos dois exemplos: um que se refere ao Mercosul e à União Europeia; por fim, apresentaremos nossas conclusões mostrando que fraternidade é uma possibilidade, um desafio e uma aposta.

A metodologia que utilizamos está diretamente relacionada com o processo de transformação social, já que metá, etimologicamente, significa transformação e sucessão no tempo, e theoría, a ação de observar. Ou seja, ao mesmo tempo em que a metateoria é objeto, também é produto de pesquisa. Ademais, ao utilizar a metateoria do direito fraterno, o sujeito se coloca na própria análise; por isso, a não separação entre sujeito e objeto. Eligio Resta, quando afirma que a sua teoria é uma metateoria, mostra a necessidade de agregar vários pressupostos para a análise da complexidade social. Assim como utiliza muitos pressupostos da teoria sistêmica, também trabalha com a teoria habermasiana, com os pressupostos da psicanálise, da filosofia, entre outros.

Os principais pontos desta metateoria que nos interessam para este artigo são os seguintes: a fraternidade como possibilidade e necessidade de ver o outro como um outro eu; os pactos que são estabelecidos entre pares, nos quais não existe lugar para um soberano; a necessidade de superar o dogma da soberania dos Estados; a não violência e a inclusão sem limites, mesmo sabendo que muitas vezes temos uma inclusão que se dá por meio da exclusão. Por isso, a metateoria do direito fraterno apresenta-se como anacrônica e, ao mesmo tempo, como uma aposta no processo de transformação social. Neste processo, o direito à saúde é um tema que ultrapassa as fronteiras de todos os tipos, pois a ideia do outro como irmão não suporta delimitações territoriais, nem outras delimitações. Para Resta, a fraternidade referida na revolução iluminista continua inédita e não resolvida em relação à igualdade e à liberdade, e retorna agora vinculada à ideia de globalização e à necessária ruptura de fronteiras, na qual a condição de dependência de tudo e de todos é cada dia mais evidente. Assim, ao mesmo tempo em que cresce o sentimento de que tudo poderia ser diferente do que ocorre, mas se pode fazer pouco para que este diferente efetivamente ocorra, temos também o pensamento na ligação uni-versali capaz de interpretar o presente, cujo nosso tempo, como afirma Resta, vive uma rearticulação decisiva 
na ideia de spazi politici, e exatamente por isso impõe um repensar no léxico dos nossos conceitos, como o de fraternidade, que se manteve em silêncio por muito tempo, mas se apresenta agora com mais força, ainda que de modo anacrônico.

A metateoria do direito fraterno pressupõe o desvelamento de paradoxos, ou seja, como é possível, em uma sociedade cosmopolita, termos fronteiras ainda intransponíveis? E, de fato, elas são instransponíveis? Qual a função da fraternidade neste jogo? Sobre estas indagações, temos muito ainda a refletir, mas é fundamental entender o que significa o direito fraterno, suas possibilidades e suas limitações.

Para aprofundar a discussão que ora propomos, teremos como focos explicativos duas situações: a primeira se refere à situação transfronteiriça no Mercosul e a segunda diz respeito à situação dos imigrantes na União Europeia; ambos tratam do direito à saúde ou da falta dele. No caso Mercosul, apresentaremos a situação do fechamento do único hospital em Santana do Livramento e a solução encontrada pelas comunidades de zonas de fronteira; no caso da União Europeia, falaremos do acesso aos serviços de saúde para a população migrante e do controle policial de quem acessa o serviço de saúde.

Abordaremos os pressupostos desta metateoria relacionando-os, durante toda nossa reflexão, com o sistema da saúde e com a aposta que fazemos na construção de uma sociedade em que o direito efetivamente possa contribuir para a ruptura de fronteiras que impedem uma cidadania cosmopolita. Acreditamos que a fraternidade apresenta-se como um caminho para a consolidação dos direitos fundamentais, pois o resgate deste pressuposto iluminista, ao mesmo tempo em que traz novos desafios, recupera a velha ideia de ver o outro como um outro EU; mais do que isso, a fraternidade está fundada na lei da amizade, no compartilhar, no pactuar. Talvez por isso ela tenha ficado escondida nas masmorras da Revolução Francesa, mas é preciso resgatá-la; e a saúde é, sem dúvida, um bom lugar para desvelar este pressuposto.

Retomaremos o esquecimento/lembrança da fraternidade, já que seu lugar não foi preenchido por outros pressupostos; ele ficou vago, mas agora retorna com força, já que os demais pressupostos da revolução iluminista não conseguiram efetivar políticas públicas capazes de incluir sem excluir. Entretanto, eles só fazem 
sentido em uma sociedade disposta a apostar! O sentido desta aposta está na percepção e na inclusão do outro.

Por meio dos casos que relataremos, veremos que a vida nestes lugares tem muitas dificuldades, bem como muitas facilidades ou, como tradicionalmente estamos falando, temos muitas possibilidades aliadas a muitas limitações. Estas limitações são cotidianamente superadas por meio das "invenções" das populações transfronteiriças, bem como com o envolvimento dos trabalhadores da saúde, mostrando que é possível e necessário ultrapassar as barreias daquilo que está escrito na lei, ou, ainda, entender este nascimento de um direito difuso: "Sta forse nascendo um diritto diffuso e mobile, che disegna una terra di tutti e di nessuno, e che puo paradossalmente divenire strumento di liberazione da una regola obbligante che pretende di chuidere la vita in una gabbia giuridica". ${ }^{3}$

$\mathrm{Na}$ sociedade atual, podemos identificar constantemente os limites de um direito fundado na ideia de Estado-nação e ver suas maiores possibilidades. Temos, como diz Rodotà, um direito difuso que ao mesmo tempo desenha a terra de todos e de ninguém; entretanto, quais as implicações desta concepção de sociedade e direito para a efetivação do direito à saúde como um bem da comunidade?

É interessante observar que os habitantes destas zonas criam suas próprias regras de convivência, as quais funcionam muito mais que o direito de cada Estado-nação, sem excluir a importância das legislações internas que conseguem criar e recriar ${ }^{4}$ e, muitas vezes, o sistema do direito apresenta fortemente suas limitações e impedimentos para o processo de um direito efetivamente fraterno. Notemos que recentemente o sindicato médico do RS, mais uma vez, "venceu" (o que não é uma vitória; é, muito pelo contrário, um grande retrocesso) a questão da possibilidade de os médicos uruguaios trabalharem na fronteira Rio Grande do Sul-Uruguai. A possibilidade de os médicos, assim como outros profissionais da saúde, trabalharem fora do país onde foram titulados muda a cada dia, em

3 RODOTA, Stefano. La vita e le regole. Tra diritto e non diritto. Feltrineli, Milano, 2006, pg.62 [Tradução livre: Está talvez nascendo um direito difuso e móvel, que desenha uma terra de todos e de nenhum, e que pode paradoxalmente tornar-se instrumento de liberação de uma regra coativa que pretende fechar a vida em uma gaiola jurídica].

4 Aqui também podemos pensar nos vários significados do pluralismo jurídico e seu impacto na vida cotidiana. Tradicionalmente o pluralismo jurídico é entendido como "corrente doutrinária que insiste no fato de que à pluralidade de grupos sociais correspondem sistemas jurídicos múltiplos compostos que seguem relações de colaboração, coexistência ou negação [...]". André - Jean ARNAUD et al. Dicionário enciclopédico de teoria e sociologia do direito, pg. 589. 
função da judicialização da questão. Notemos que não é apenas um problema de revalidação do título, pois esta situação já está regulamentada, o problema é o que foge da lei. Esta é uma fronteira para a efetivação da fraternidade.

Esta situação nos faz refletir sobre o limite do direito centrado na delimitação geográfica ou territorial. É oportuno recordar que Kant (autor importante na construção da metateoria do direito fraterno) já trazia a ideia de uma República Mundial, ou seja, ele pretendia a constitucionalização do direito internacional. Este ponto é retomado com muita ênfase por Habermas, especialmente no texto "Ocidente Diviso", no qual há um capítulo sobre "Dal diritto degli Stati al diritto dei cittadini del mondo". Habermas nos mostra que pensar nesta perspectiva inviabiliza as guerras como forma de resolver os conflitos, exatamente porque em uma sociedade cosmopolita não existe o externo, mas o interno, a inclusão, mesmo que esta inclusão possa ser geradora de exclusão, mas não parte do pressuposto excludente. Como observa:

L'idea della condizione cosmopolitica è più ambiziosa, perchè traspone dal piano nazionale a quello Internazionale la positivizzazione dei diritti civili e di quelle umani. Il núcleo innovativo di quest'idea sta nella conseguenza rappresentata dalla conversione del diritto internazionale, in quanto diritto degli Stati, in un diritto cosmopolitico in quanto diritto di individui; ora questi sono soggetti giuridici non più soltanto come cittadini dei loro rispettivi Stati, ma egualmente come membri di una comunità cosmopolitica de un único sovrano. ${ }^{5}$

Notemos que, com a metatoria do direito fraterno, esta perspectiva aparece criticada, pois a ideia de um único soberano pode ser complexa. Eligio Resta fala em uma constituição sem Estado; além disso, é um direito que abandona os confins fechados de cidadania e observa uma nova forma de cosmopolitismo. Esta nova forma de observar não é a mercadológica, mas é centrada na afirmação da inderrogabilidade universal dos direitos humanos.

Oportunas também são as reflexões de Sabino Cassese, o qual questiona a relação entre globalização, Estado democrático de direito e democracia. 0

5 HABERMAS, Jurgen. L'occidente diviso. Traduzione di Mario Carpitella. Editori Laterza. Roma-Bari, 2005, pg. 117. [Tradução Livre: A ideia da condição cosmopolita é mais ambiciosa porque transpõe do nível nacional para o internacional a positivação dos direitos civis e dos direitos humanos. O núcleo inovador desta ideia está na consequência representada pela conversão do direito internacional como direito dos Estados, em um direito cosmopolita como direitos de um indivíduo; esses são sujeitos jurídicos, não somente como cidadãos de seus respectivos Estados, mas igualmente como membros de uma comunidade cosmopolita de um único soberano]. 
Novos Estudos Jurídicos

problema fundamental e sem resposta é: existem limites para a democratização produzida pela globalização? Quão universal e universalizantes são os princípios da democracia? Ou nas palavras do autor: "[...] la democrazia globale sviluppa o sustituisce le democrazie nacionali? E non potrebbero gli ordini giuridici globali abusare, a loro volta, dei poteri di cui dispongono, sai pure a fini giusti?"6

O questionamento do autor é fundamental, pois uma sociedade além do Estado existe e tem regras muito claras (alguns chamam inclusive de neoliberal), mas realmente é possível uma ordem jurídica além ou acima do Estado? A União Europeia, que lição nos dá? E o Mercosul, pode ser uma ordem jurídica além dos Estados? Qual transformação queremos?

A estas observações, podemos agregar o atual e oportuno modo que temos de ver o outro, de ver o diferente, pois o outro só deixará de ser "o diferente" quando o "eu" não apenas andar com ele, mas quando se dispuser a viver entre e com o outro. Evitamos cotidianamente este outro porque não estamos dispostos a enfrentar e afrontar as consequências desta aproximação, porém somente ela será capaz de efetivar uma "outra" civilização, o que já foi advertido por Levinás, quando nos diz que a possibilidade de superar a crise da civilização ocidental pode ser observada na relação (ou não) do outro com o eu, ou, ainda, para o autor, não basta encontrar o outro, acolhê-lo, falar: é necessário assumir responsabilidade. Observamos ainda que ele (Levinás) propõe a aceitação do outro ainda que diverso, considerando-o uma riqueza, um bem e um valor próprio desta sua alteridade, uma diferença que não impede de identificar no outro um outro eu. Sinteticamente, este aspecto interessa muito para nosso estudo; Levinás busca constantemente o outro, quer eliminar o egoísmo e a indiferença, mostrando uma nova dimensão do eu, não um indivíduo isolado, mas um indivíduo que compreenda em si também o outro e em tal modo de vida um novo gênero de pessoa e de existir.

\section{AS FRONTEIRAS DA SOCIEDADE COSMOPOLITA FRENTE À (DES) NECESSIDADE DA SOCIEDADE DE FRONTEIRAS}

Nesta sociedade, precisamos continuamente construir e desconstruir fronteiras ${ }^{7}$, que foram construídas com muitas lutas, com muito sangue, suor $e$

6 CASSESE, Sabino. II diritto Globale. Giustizia e democrazia oltre lo satto. Enaudi, Torino, 2009, pg. 166167. [Tradução livre: A democracia global desenvolve ou substitui as democracias nacionais? $\mathrm{E}$ não poderiam as ordens jurídicas globais abusarem, por sua vez, dos poderes aos quais dispõem, para os ditos fins justos?]

7 Conforme OLIVEN, Ruben. Fronteiras; arte e pensamento na época do multiculturalismo. Fernando Schuler e Marília de Araujo Barcellos (orgs). Porto Alegre: Sulina, 2006, pg. 157: Embora as noções de territórios e de 
lágrimas. Sabemos que esta construção nem sempre se deu atendendo o desejo da população que vivia nestas zonas fronteiriças e/ou como migrantes; entretanto, era preciso definir quem era o proprietário da terra, para assim explorá-la até onde fosse possível. Hoje, vemos a necessidade constante de ultrapassar as fronteiras que, muitas vezes, não estão demarcadas pela natureza, mas pelas nossas formas históricas de discriminação e produção constante de desigualdade social. As fronteiras, durante muito tempo, serviram para separar, para dividir; agora, é hora de pensar na unificação: os eventos sociais requerem a superação destes limites. Na busca constante dessa superação, construímos, muitas vezes, outros limites, como os da burocracia, que impedem a livre circulação de ideias e de solidariedade. É esta transformação social que queremos, que constantemente buscamos, por isso a necessária luta por esta utopia possível.

A aposta no pressuposto da fraternidade acontece porque, por meio dele, é possível superar a inimizade e as diversas formas de guerra que se mascaram na sociedade global. Assim, a fraternidade retorna com força diante da crise do Estado-nação e da necessidade de solidificar uma sociedade cosmopolita, na qual a humanidade é ameaçada somente pela própria humanidade, como observamos com diversos autores: Resta, Ferrajoli, Arenth, entre outros. Vale recordar que os pressupostos do direito fraterno não servem apenas para grandes dimensões, conforme Resta:

Vi è da aggiungere che il diritto fraterno non vive soltanto nella dimensione dei grandi spazi cosmopoliti dove agiscono geopolitiche e mondializzazioni sempre sospette: si referisce ai piccoli problemi dei conflitti quotidiani e alle <<lotte >> individuali, esattamente come ne parlava Jhering. Per questo bisogna soffermarsi su quella singolare esperienza della giurisdizione e sulla sapienza giudiciaria del conflitto che ha bisogno di un redimensionamento ecologico: meno legato allo Stato e più presente nelle relazioni sovranazionali. ${ }^{8}$

fronteira tenham existido em diferentes momentos históricos, seus significados variam no tempo e no espaço. "[...] Desterritorialização é um termo utilizado para designar fenômenos que se originam num espaço e que acabam migrando para outros".

8 RESTA, Eligio. In: Globalizzazione e diritti futuri. A cura di R. Finelli, F. Fistetti, F.R. Recchia Luciani, P. Di Vittorio. Ministero dell'Istruzione. Roma: Università e Ricerca scientifica, 2004, p.116 [Tradução livre: É de ser acrescentado que o direito fraterno não vive somente na dimensão dos grandes espaços cosmopolitas, onde agem a geopolítica e a mundialização sempre suspeitas: refere-se aos pequenos problemas dos conflitos cotidianos e às 'Iutas' individuais, exatamente como nos falava Jhering. Por isso é preciso firmar-se sobre aquela única experiência da jurisdição sobre a sabedoria jurídica do conflito que necessita de um redimensionamento ecológico: menos ligado ao Estado e mais presente nas relações supranacionais]. 
O tema do direito à saúde é propício para mostrara fraternidadee a solidariedade como possíveis no plano concreto. Esta humanidade que ameaça constantemente a própria humanidade pode também produzir uma não ameaça. Mesmo sabendo que a sociedade cosmopolita é também o logos da ambivalência, vemos que, por meio da busca da saúde - como bem da comunidade - esta ambivalência pode refletir-se na cooperação entre estados e povos. Trataremos deste aspecto quando relatarmos o caso de Santana do Livramento, onde esta singolare esperienza della giurisdizione efetivamente ocorreu. Ainda assim, é importante assinalar que o pressuposto da fraternidade não está apenas no campo teórico: temos práticas cotidianas em fronteiras que mostram as possibilidades concretas da efetivação de um dos pressupostos da revolução iluminista que ficou "guardado"; assim, a transformação social sai do plano utópico para o concreto, criando, obviamente, novas utopias, porém efetivando uma nova forma de relação social.

Somente na identificação deste paradoxo da ambivalência da fraternidade que nos damos conta de que a oportunidade de regular o mundo só é possível estando no próprio mundo, ou, ainda, cada determinação de mundo apenas pode ser realizada na sociedade e só por meio desta. Do mesmo modo, a indeterminação do mundo significa que este pode ser determinado, sempre de modo diverso: historicamente, o mundo vem sendo delimitado, medido, dividido e apropriado. Esta história pode ser alterada; é preciso entender a sociedade como um local possível de transformação social. As fronteiras fazem parte desta sociedade em que os eventos ocorrem de modo simultâneo, independentes das vontades individuais e locais, mas influenciando diretamente as nossas vidas cotidianas. Assim, as ameaças fronteiriças podem ser resolvidas no próprio espaço, pois, fora dele, qualquer solução será inadequada. Não temos dúvidas sobre a ambivalência da vida em territórios que confinam. Por isso, a política pública deverá superar esta situação buscando novos caminhos. Não basta reafirmarmos a impotência dos mecanismos estabelecidos; é necessário transformar esta ambivalência em algo positivo. Tendo presente que no processo evolutivo desvelamos paradoxos criando novos, também resolvemos ambivalências criando novas ambivalências. O conceito de fronteiras é muito propício para esta discussão, como podemos observar por meio desta definição: 
As zonas fronteiriças são zonas de empréstimos e apropriações culturais e, por isso, um lugar privilegiado para a compreensão do fenômeno migratório internacional. Essas fronteiras tanto podem se configurar como lugar de controle como de transgressão, seja das fronteiras geopolíticas, seja das fronteiras culturais e da subjetividade ${ }^{9}$.

Esta definição nos remete à reflexão sobre os aspectos positivos que podemos identificar nestes espaços de empréstimos e apropriações culturais. É frequente encontrarmos, nas cidades que fazem fronteira com o Brasil, um terceiro idioma: o portunhol, ou ainda uma cidadania mista "os brasiguayos", são formas de apropriação encontrada pelos habitantes dessas regiões, revelando que, de fato, a fronteira é um lugar onde as subjetividades se apresentam. A saúde assume, diante da sociedade de mundo, um status de "internacionalidade". É a partir disso que podemos pensar em um novo modelo de saúde pública internacional e, diante desses novos desafios, podemos refletir, também, sobre um novo paradigma com pilares na solidariedade, na justiça social e na fraternidade, ou seja, na saúde como um bem comum público global baseado em uma ideia de governança da saúde, pois é inviável imaginar que os países integrantes do bloco Mercosul ainda ajam de modo isolado nas questões de saúde, levando em conta tão somente os seus sistemas internos de saúde e não a dimensão social das doenças.

Evidentemente, quando tratamos de fronteiras, podemos buscar várias definições ${ }^{10}$, mas é fundamental retornar à ideia originária: a lei da terra é a lei da guerra, o sentido no nomos é de apropriação da produção e da distribuiç̧ão, que:

[...] pone ogni sovranità statale come oggetto di un'apprensione violenta e sottoposta quindi a una rivalità mimética e concorrente di ogni altro Stato. E si tratta di Stato, non di popolo, che vive di apprensione violenta di un teritorio, che transforma ogni idea di com-fine in fronteira, che include qualcosa prechè esclude, che riproduce al interno ed sporta all'esterno la forma dell' opposizione tra amici e nemice ${ }^{11}$.

9 RODRIGUES, Francilene. Migração transfronteiriça na Venezuela. Estud. 2006, vol.20, n.57, pp. 197-207. Disponível em: <http://www.scielo.br/scielo.php?pid=S010340142006000200015\&script=sci_arttext>. Acesso em $14 / 04 / 16$.

10 Uma nova percepção do conceito de fronteira é dada por Bauman, quando mostra que o evento de 11 de setembro de 2001 agrega à ideia de fronteira a questão do terrorismo; mais do que isso, o autor afirma que: "o espaço global assumiu o caráter de uma terra de fronteiras." (BAUMAN, Zygmunt. La società sotto assedio. Tradução de Sergio Minucci. Editori laterza, Roma- Bari, 2005, pg. 86.)

11 FISTETTI, R. Finelli; LUCIANI, F. R.; VITTORIO, P. Globalizzaione e diritti futuri. Roma: Manifestolibri, 2004. pg. 31. [Tradução livre]: Coloca cada soberania estatal como objeto de uma apreensão violenta e submissa, então, sobreposta a uma rivalidade mimética e concorrente de cada outro Estado. E se trata de Estado, não de povo, que vive de apreensão violenta de um território, que transforma cada ideia de confim em fronteira, que inclui qualquer coisa porque exclui, que reproduz no interior e exporta para o exterior a forma de oposição entre amigo e inimigo. 
$\mathrm{Se}$, originariamente, as fronteiras representavam este espaço de luta entre amigos e inimigos, hoje podemos ver outras dimensões não violentas da fronteira. Ou melhor, ela não pode ser mais o locus de disputa entre nações, ou ainda algo que divide e limita.

Assim, analisaremos alguns dos tratados e dos acordos entre o Brasil e os países fronteiriços e, para isto, buscamos as legislações disponíveis no Ministério das Relações Internacionais (http://www2.mre.gov.br/dai/Home.htm) prioritariamente. Trataremos da questão dos Migrantes, em que destacaremos situações vivenciadas tanto no nosso Continente como na União Europeia.

\section{UM ESPAÇO DE TODOS E PARA TODOS: MIGRANTES E SAÚDE}

Lemos na declaração final Migrações e direitos humanos na X Cúpula Social do Mercosul o seguinte enunciado: Por um Mercosul livre de xenofobia, racismo e toda forma de discriminação ${ }^{12}$.

Esta declaração é importante, pois, pela primeira vez, a cúpula do Mercosul enfrenta a questão da migração como uma questão de direitos humanos. O Mercosul, para ser efetivado, precisa de muitas reflexões na área dos direitos humanos, e o que temos até agora é uma distância muito grande entre o que é apresentado nos tratados, acordos, convênios e a realidade das populações migrantes e fronteiriças. Embora saibamos que há muito a ser feito para a efetivação destes direitos, a positivação deles é importante na medida em que se apresenta como um instrumento de luta, um direito que já existe na rua, pois esta é um espaço público.

Ora, pensar um Mercosul livre de xenofobia, racismo e toda forma de discriminação significa a necessidade de retomarmos o pressuposto anacrônico da fraternidade ${ }^{13}$.

A referida declaração fala da humanização das políticas migratórias por meio de quinze pontos, todos referindo sempre a importância de reforçar as convenções internacionais, a inclusão, a defesa de uma política comum, entre

12 Declaração final Migrações e direitos humanos na X Cúpula Social do Mercosul. Disponível em: <http://www. migrante.org.br/IMDH/fckeditor/editor/filemanager/connectors/aspx/userfiles/ file/Migrantes/DECLARAO\%20 FINAL\%20Foz\%20do\%20lguau\%20dez2010.pdf>. Acesso em 14/04/16.

13 RESTA, Eligio. II diritto fraterno. Editori Laterza: Roma/Bari, 2009. 
outros aspectos. Já no ponto quatro lemos: Propomos a criação de um conselho de políticas migratórias e integração dos povos no âmbito da UNASUL, como instância política e decisória ${ }^{14}$.

Interessante observar que, sempre que as cúpulas se reúnem, transferem decisões que poderiam tomar e criam "conselhos ou comissões", desconsiderando toda experiência já vivenciada e denunciada pela população migrante. O ponto cinco também interessa para a nossa reflexão: Exigimos que o direito à saúde seja garantido a todas e a todos sem discriminação, com ações que impliquem em acesso tanto a medidas preventivas como a ações de tratamento, sempre levando em conta o contexto migratório das pessoas e os aspectos culturais específicos ${ }^{15}$.

Notemos que este ponto reforça a ideia de saúde como bem comum da comunidade, e que o respeito à cultura está implicado no direito à saúde. Quando buscamos no cotidiano, dificilmente encontramos práticas em saúde que respeitem aspectos sanitários culturais de populações indígenas ou afrodescendentes. Novamente observamos que a efetivação de qualquer legislação depende da luta do povo.

A luta pelo direito à saúde no Brasil vem ganhando espaço graças à importância do controle social, que tem tido uma função imprescindível para definição dos rumos da saúde como um direito humano fundamental, como afirma Ferrajoli ${ }^{16}$. A declaração continua afirmando os direitos humanos, como podemos observar:

6 - Exigimos que o direito à educação seja garantido a todas e a todos sem discriminação independentemente de sua situação migratória. Nenhuma criança, adolescente ou adulto migrante pode ter seu acesso à educação negado. Para o pleno acesso a este direito, devese considerar o contexto migratório das pessoas, aspectos culturais específicos e o reconhecimento da validade dos títulos acadêmicos regionais ${ }^{17}$.

14 Declaração final Migrações e direitos humanos na X Cúpula Social do Mercosul. Disponível em:< http://www. migrante.org.br/IMDH/fckeditor/editor/filemanager/connectors/aspx/userfiles/ file/Migrantes/DECLARAO\%20 FINAL\%20Foz\%20do\%20lguau\%20dez2010.pdf>. Acesso em 14/04/16.

15 Declaração final Migrações e direitos humanos na X Cúpula Social do Mercosul. Disponível em: $<$ http://www. migrante.org.br/IMDH/fckeditor/editor/filemanager/connectors/aspx/userfiles/ file/Migrantes/DECLARAO\%20 FINAL\%20Foz\%20do\%20Iguau\%20dez2010.pdf>. Acesso em 14/04/16.

16 FERRAJOLI, Luigi. Principia iuris. Teoria del diritto e della democaracia.Teoria della democrazia. v. 1. Editori Laterza: Roma- Bari, 2007, pg. 725-726.

17 Declaração final Migrações e direitos humanos na X Cúpula Social do Mercosul. Disponível em: <http://www. 
Ora, o que temos, na prática, é o completo desrespeito a esta situação, na medida em que, para garantir este direito e outros, muitas vezes os profissionais formados no âmbito do Mercosul precisam recorrer ao judiciário, como é o caso da Fundação Hospital de Caridade de Quaraí (RS), que pôde manter em seus quadros cinco médicos uruguaios que já atuavam na instituição e contratar outros, caso seja necessário.

A decisão - em antecipação de tutela - é decorrência do indeferimento de liminar nos autos de ação civil pública ajuizada pelo Cremers contra o nosocômio e os profissionais, na qual o conselho de classe pretende a imediata suspensão do exercício das atividades dos médicos no Hospital de Caridade, sob a alegação da inexistência de revalidação dos diplomas em universidades brasileiras e de inscrição na entidade.

O Cremers quer, ainda, a imposição ao hospital do dever de rescindir os contratos e de não mais contratar médicos uruguaios em tais circunstâncias e a imposição aos médicos da proibição de exercer a medicina em território brasileiro.

Interessante também acompanhar a página do Sindicato Médico do Rio Grande do Sul, na qual esta notícia é informada, concluindo com as palavras do presidente: "O juiz que autoriza médico estrangeiro a trabalhar no Estado, mesmo sem diploma revalidado, será responsabilizado no caso de um erro que esse profissional venha a praticar?"18

Esta situação está longe de ser resolvida. Enquanto isso, continuamos não efetivando o direito à saúde dos migrantes e não migrantes e sofrendo as consequências deste processo no dia a dia.

Retornando para a declaração, observamos que ela, como não poderia ser diferente, embora devesse, termina propondo a criação de mais um "Conselho": 15 - Propomos a criação de um Conselho Consultivo de Migrações do Mercosul integrado por organizações de migrantes ${ }^{19}$. 
Mais uma vez, transferimos para o futuro aquilo que não "desejamos" resolver. Quem efetivamente podemos definir como migrante? Uma das possíveis respostas é dada pela página inicial do Instituto de Migrações e Direitos Humanos:

Migrante é, pois, toda a pessoa que se transfere de seu lugar habitual, de sua residência comum, ou de seu local de nascimento, para outro lugar, região ou país. "Migrante" é o termo freqüentemente usado para definir as migrações em geral, tanto de entrada quanto de saída de um país, região ou lugar. Há, contudo, termos específicos para a entrada de migrantes - Imigração - e para a saída - Emigração. Há, também, "migrações internas", para referir os migrantes que se movem dentro do país, e "migrações internacionais", referindo-se aos movimentos de migrantes entre países, além de suas fronteiras ${ }^{20}$.

A situação dos migrantes no mundo todo não acompanhou o processo de globalização, isto pode ser identificado com as situações diárias que ocorrem nos países da União Europeia. Os reflexos disso são percebidos também na saúde, por exemplo, a tuberculose, doença quase inexistente em países europeus passa a reaparecer, causando muitos danos à população geral. Não temos dificuldades de globalizar a economia e flexibilizar as relações de trabalho, porém a efetivação dos direitos sociais ainda está longe de ser alcançada. O modelo econômico dominante, conforme Negri e Hard, segue necessitando dos pobres, pois estes expressam uma enorme força vital e mais do que isso, segundo os autores:

Os migrantes constituem uma categoria especial dos pobres que demonstra essa riqueza e produtividade [...] Muitas vezes os migrantes podem viajar de mãos vazias em condições de extrema pobreza, mas ainda assim estão cheios de conhecimento, linguagens, habilidades e capacidades criativas: cada migrante traz consigo todo um mundo [...] A riqueza dos migrantes está em parte em seu desejo de algo mais, em sua recusa de aceitar as coisas como são ${ }^{21}$.

Os migrantes que chegam e permanecem no Brasil têm confirmado estas observações de Negri e Hard, pois de fato são categorias especiais. Mesmo com muitas limitações financeiras (somente estes migrantes têm

20 Instituto de Migrações e Direitos Humanos. Disponível em: < http://www.migrante.org.br/ IMDH/ControlConteudo. aspx?area=8d00b920-e735-4147-87a6-c1caa8feb528>. Acesso em 14/04/16.

21 KOHAN, Néstor. O Império de Hardt \& Negri: para além de modas, 'ondas' e furores. En publicacion: Filosofia Política Contemporãnea: Controvérsias sobre Civilização, Império e Cidadania. Atilio A. Boron, 1a ed. - Buenos Aires: Consejo Latinoamericano de Ciencias Sociales - CLACSO; São Paulo: Departamento de Ciência Política. Faculdade de Filosofia, Letras e Ciências Humanas. Universidade de São Paulo, 2006, p. 180-181. 
dificuldades), contribuem para a formação do que hoje conhecemos como cidadão transfronteiriço, e isso fica evidente nos aspectos culturais, religiosos, políticos, culinários. Temos, hoje, nas longas fronteiras, diversos exemplos de uma convivência sociocultural fundada na fraternidade. Porém, a situação se apresenta de outro modo quando se trata de igualdade de direitos: muitas vezes, estes cidadãos transfronteiriços ficam à margem de direitos e somente por meio do judiciário têm o direito à saúde, por exemplo, assegurado, como podemos observar por meio dos seguintes mandados de segurança.

Decisão importante 22 , em mandado de segurança, contra o Estado do Mato Grosso, decidiu acolher o pedido de autora, de nacionalidade boliviana, para retirada de tumor cerebral com riscos de morte, cuja decisão foi a seguinte:

\begin{abstract}
A saúde constitui direito social fundamental que deve ser garantido indistintamente aos brasileiros e aos estrangeiros residentes no país, nos termos do arts. 5, caput, e 196, da Constituição Federal. A viabilização e real efetivação do direito à saúde é obrigação primordial do ente público, a quem compete realizar o procedimento cirúrgico, que se mostra essencial para a preservação da vida, e o cidadão não detém condições financeiras de arcar com seu custeio". (Reexame Necessário da $5^{a}$ Vara Especializada da Fazenda Pública de Cuiabá - MT, nos autos do MS n 157/2003 - Rel. Rubens de Oliveira Santos Filho)
\end{abstract}

Ou seja, estes dois mandados reforçam a ideia de que saúde é um direito fundamental, e que o acesso a este direito precisa ultrapassar os limites geográficos e políticos. Em outros termos: a saúde é um bem da comunidade; no caso das regiões de fronteira e com a população migrante, é preciso que o sistema do direito possa decidir conforme o direito vivo daquela comunidade. Como já afirmava Ehrlich, o centro da gravidade do direito não está na legislação, nem na ciência do direito, nem na jurisprudência, mas na própria sociedade. Assim, faz sentido a abordagem atual de Eligio Resta para o direito vivente:

Il diritto vivente comincia a essere qualcosa che racchiude e acumuna

22 EMENTA: SISTEMA ÚNICO DE SAÚDE. TRANSPLANTE DE MEDULA. TRATAMENTO GRATUITO PARA ESTRANGEIRO. ART. $5^{\circ}$ DA CF. $O$ art. $5^{\circ}$ da Constituição Federal, quando assegura os direitos e garantias fundamentais a brasileiros e estrangeiros residente no País, não está a exigir o domicílio do estrangeiro. $O$ significado do dispositivo constitucional, que consagra a igualdade de tratamento entre brasileiros e estrangeiros, exige que o estrangeiro esteja sob a ordem jurídico-constitucional brasileira, não importa em que condição. Até mesmo o estrangeiro em situação irregular no País se encontra protegido e a ele são assegurados os direitos e as garantias fundamentais. Agravo improvido. AGRAVO DE INSTRUMENTO No 2005.04.01.032610-6/PR RELATORA: Juíza VÂNIA HACK DE ALMEIDA. 
tutte le dimensione e pretende, quindi, di non poter essere ridoto a território <disciplinato>> dalle partizioni scientifica [...] il diritto non abita nei conceti ma nella comunità, nei gruppi, nell’esercizio concreto del potere e dell'influenza, nella religione, nella vita economica, nell'opinione pubblica ${ }^{23}$.

Assim, utilizando o conceito anacrônico de fraternidade e o direito vivente, podemos ver que o direito, assim como apresenta suas limitações, também nos dá possibilidades concretas de efetivar a transformação social. Por meio destes dois mandados, vemos que o papel do direito é fundamental para que tenhamos o direito ao direito à saúde como um bem da comunidade.

\section{LIMITES E POSSIBILIDADES PARA A SAÚDE NAS FRONTEIRAS}

A solidariedade coloca em discussão as possibilidades que temos de unificar e reduzir as distâncias. O direito à saúde é um tema que ultrapassa várias fronteiras; quando estas não são superadas e ultrapassadas pelos Estados, deixamos a iniciativa privada determinar os rumos da atenção e da promoção da saúde nestes espaços, não mais locais, mas globais:

[...] que a globalização da vida social tem impactos constitutivos no conceito de saúde que os Estados contemporâneos estão obrigados juridicamente a garantir para seus povos. E - importante notar - tais impactos decorrem não apenas das regras de direito adotados em foros internacionais, cada vez mais incontornáveis, mas também de exigências técnicas, igualmente inafastáveis. É o próprio conceito de saúde que não pode ser compreendido sem o recurso aos direitos de liberdade, de igualdade e de solidariedade entre os povos e gerações ${ }^{24}$.

O conceito de saúde deve ser compreendido desde uma perspectiva global e democrática. O problema que enfrentamos hoje - um deles - é que a democracia representativa foi privada da democracia econômica. Democracia e agenda econômica deveriam coincidir; não é possível que o futuro da humanidade continue sendo decidido pelo FMI ou pelo Banco Mundial (que de banco mundial pouco tem...). Como superar este problema? Com os tratados? Com os acordos? Quem 23 RESTA, Eligio. Diritto vivente. Eiditori Laterza, Bari, 2008, p. 29-30. [Tradução Livre]: O direito vivo começa a ser alguma coisa que fecha, acumula todas as dimensões e pretende, então, não permitir ser reduzido ao território <<disciplinado>> pelas repartições científicas... o direito não habita nos conceitos, mas na comunidade, nos grupos, no exercício concreto do poder e da influencia, na religião, na vida econômica, na opinião pública.

24 DALLARI, Sueli Gandolfi e VIDAL, Serrano Nunes Junior. Direito Sanitário. São Paulo: Editora Verbatim, 2010, p. 29. 
sabe pensar, como sugere Giovana Ricoveri, em uma democracia da terra capaz de colocar os humanos como membros da família da terra. A autora coloca como objetivo de um movimento para a democracia da terra a ideia da indivisibilidade da liberdade e de todas as espécies:

[...] la Democrazia della Terra é la democrazia di ogni vita, e non solo quella per gli umani privilegiati in ragione della classe, della razza, del genero e della religione. La Democrazia della Terra pone la responsabilitá e i doveri al centro del nostro sistema di relazioni; e i diritti derivano dalla responsabilità invece che dal paradigma dominante di diritti senza responsabilità e responsabilità senza diritti ${ }^{25}$.

Vemos que um dos lugares ou canteiros do direito fraterno pode ser exatamente o espaço da fronteira, onde os cidadãos vivem e convivem a partir de construções próprias, identificando aquele lugar como seu, onde a democracia, em que pese suas dificuldades, torna-se possível. A Europa, ao seu modo, não conhece este espaço de fronteira, e o processo de construção de uma área político/institucional comum parece representar um primeiro e significativo passo em direção a uma ideia de cidadania que se libera da dependência dos confins. E também aqui, que não menos dramático é o problema de um direito que se afasta da dimensão da fraternidade e da solidariedade, a análise das políticas migratórias é tão significativa porque as reivindicações e os obstáculos postos pelos Estados-membros mostram a incapacidade de imaginar uma dimensão inclusiva em que o espaço comum seja a Europa.

A despeito de uma normativa comunitária que se ocupa de reconstrução (reencontro) familiar, acesso ao trabalho, tutela das mulheres e, em geral, reserva amplo espaço à tutela dos direitos da pessoa, o tema da imigração continua a ser guardado na perspectiva da contraposição amigo-inimigo. A questão do migrante se torna assim uma questão completamente política, que se carrega de uma forte valentia ideológica. A distinção entre estrangeiro regular e estrangeiro irregular parece reafirmar por que fixa as condições de "convivência", define as coordenadas de "pertencimento". Em realidade, essa divide, contrapõe, exclui

25 RICOVERI, Giovana (org). Capitalismo Natura e Socialismo. Milano: Jaca Book, 2006. p. 280. [Tradução livre]: A Democracia da Terra é a democracia de cada vida, e não somente aquela para os homens privilegiados em razão da classe, da raça, do gênero e da religião. A Democracia da Terra põe a responsabilidade e os deveres no centro do nosso sistema de relações, e os direitos derivam da responsabilidade em vez de derivar do paradigma dominante dos direitos sem responsabilidade e responsabilidade sem direitos. 
e, enfim, esquece a pessoa. Sobre o fundo de tais políticas, está a ligação da questão da imigração aos temas da crise econômica, da segurança e da luta contra o terrorismo, medo do qual a Europa não parece liberar-se. Não por acaso a França introduziu limites ao exercício do trabalho por parte dos estrangeiros, enquanto na Espanha foi criada uma exceção ad hoc a respeito do princípio do direito ao trabalho para com os cidadãos da Romênia.

O local de verificação desta lógica excludente é o direito à saúde que - não obstante as declarações - parece não conseguir liberar-se completamente da condição espacial da cidadania. Diversas políticas sanitárias, diversos medos de entender o processo de integração, diferentes contextos culturais impõem mais de um obstáculo à realização de uma fraternidade, que se liberando dos vínculos da cidadania, coloque em "jogo um novo modelo de comunidade política"26.

\section{MARCOS NORMATIVOS: TRATADOS E ACORDOS BINACIONAIS NA ÁREA DO MERCOSUL}

Entender a complexidade do tema do direito à saúde nas fronteiras passa necessariamente pelo conhecimento dos instrumentos jurídico-normativos que temos. Embora exista uma grande distância entre a criação de uma lei e sua efetivação, ela é fundamental para que possamos concretizar o direito ao direito à saúde.

Os acordos que citaremos a seguir expressam claramente a necessidade de entender o locus fronteiriço desde uma perspectiva de efetivação da fraternidade e da solidariedade entre a população. Por exemplo, destacaremos dois acordos entre Brasil e Argentina. O primeiro, firmado em 30.11.2005 (http://www2.mre. gov.br/dai/b argt 402_5639.htm), propõe, entre outros aspectos, os seguintes:

[...] criar instrumentos que promovam a maior integração das
comunidades fronteiriças, buscando melhorar a qualidade de vida de
suas populações [...] facilitar a convivência das localidades fronteiriças
vinculadas e impulsar sua integração através de um tratamento
diferenciado à população em materia econômica, de trânsito, de
regime trabalhista e de aceso aos serviços públicos e de educação.

Quando falamos em qualidade de vida, tratamos de saúde. Basta observarmos o que é apresentado no relatório de determinantes sociais em saúde (http:// 26 RESTA, Eligio. II diritto fraterno. Editori Laterza: Roma/Bari, 2009. 
www.cndss.fiocruz.br/pdf/home/relatorio.pdf), especificamente no capítulo "Condições de vida, ambiente e trabalho".

O acordo também trata de aspectos diretamente relacionados com a saúde:

\begin{abstract}
Atendimento médico nos serviços públicos de saúde em condições de gratuidade e reciprocidade. [...] As Instituições Públicas responsáveis pela prevenção e o combate a enfermidades, assim como pela vigilância epidemiológica e sanitária das Partes deverão colaborar com seus homólogos nas localidades fronteiriças vinculadas para a realização de trabalhos conjuntos nessas áreas. Este trabalho será efetuado conforme as normas e procedimentos harmonizados entre as Partes ou, em sua ausência, com as respectivas legislações nacionais.
\end{abstract}

Observamos que do ponto de vista legislativo-jurídico, a proteção dos cidadãos tanto brasileiros quanto argentinos está assegurada por meio das instituições públicas. Porém, as informações das populações que moram nas fronteiras são que nem sempre ocorre esse intercâmbio entre os países, ficando o cidadão muitas vezes desprotegido e buscando, com isso, soluções alternativas e muitas vezes ilegais. Por exemplo, conhecemos casos de cidadãos que apresentam nas unidades de saúde endereços que não os seus para terem acesso a um atendimento básico de saúde. Obviamente, esta não é uma particularidade Brasil-Argentina, mas ela diz respeito a praticamente todos os outros países.

O trabalho conjunto que acontece em localidades fronteiriças muitas vezes ocorre, ou melhor, somente ocorre quando os operadores da saúde superam as fronteiras rígidas da burocracia. Para isto, basta ver como se dá a relação entre São Borja (Brasil) e Santo Tomé (Argentina) no que diz respeito à leishmaniose. No caso desta doença específica que atinge fortemente os dois municípios, o Rio Uruguai se transformou num oceano. Exames realizados na Argentina para detectar a doença levam 24 horas. No Brasil, mais especificamente em São Borja, os exames encaminhados para os laboratórios oficiais levam por volta de 30 dias. Embora os trabalhadores dos dois municípios tenham ações conjuntas, ainda não conseguiram superar esta fronteira.

O segundo acordo, datado de 22.08.2005 (http://www2.mre.gov.br/dai/b argt 392 5561.htm), trata do protocolo de intenções entre Ministério da Saúde do Brasil e Ministério da Saúde e Ambiente da Argentina sobre cooperação na 
área da saúde relacionada a medicamentos. Ainda que não seja restrito à situação dos fronteiriços, o acordo aborda importantes aspectos relacionados à união entre os países em prol da saúde, como:

[...] buscar uma desejável integração e coordenação nessa área, que permita o melhor aproveitamento de suas capacidades científicas, técnicas e tecnológicas, bem como de seus recursos [...] garantir o abastecimento de insumos para a produção em seus países de medicamentos essenciais e estratégicos incluindo os do Programa de HIV-AIDS, bem como aqueles para as doenças emergentes, re-emergentes e as doenças de baixa incidência e de alto custo [...] intensificar e ampliar as relações de suas respectivas agências reguladoras - Agência Nacional de Vigilância Sanitária (ANVISA), pelo lado do Brasil e, pelo lado da Argentina, a Administración de Medicamentos, Alimentos y Tecnologia Médica (ANMAT) - à luz da potencialidade da construção de uma agenda de trabalho compartilhada [...] estimular a cooperação e o intercâmbio entre os dois países no que se refere ao acesso a medicamentos e de conformidade com o Acordo de Cooperação Científica e Tecnológica, celebrado entre o Governo da República Federativa do Brasil e o Governo da República Argentina, em 17 de maio de 1980 e o Ajuste Complementar ao Acordo de Cooperação Científica e Tecnológica entre o Governo da República Federativa do Brasil e o Governo da República Argentina sobre Biotecnologia, em 30 de novembro de $1985^{27}$.

Um dos grandes sonhos de muitos trabalhadores de saúde é criar na América Latina uma soberania da saúde, iniciando pela produção de medicamentos não somenteaproduçãodemedicamentosalopáticos, mas, sobretudo, ofortalecimento e o resgate das medicinas tradicionais. Este sonho vem sendo construído nem sempre com ações integradas, porém importante citar o PLAMSUR (http://www. plamsur.com.br/). Este projeto tem como objetivo geral "melhorar a renda dos agricultores familiares, por meio da diversificação da produção com cultivo de plantas medicinais e sua inserção em cadeias de produção de fitoterápicos".

É de suma relevância uma efetiva participação das populações para que sejam ampliadas as condições de saúde. A conscientização, por exemplo, sobre os cuidados para prevenção de casos epidemiológicos como a dengue pressupõe o envolvimento de todos os habitantes das regiões afetadas e seus respectivos governos, independentemente de divisões territoriais. Somente é possível

27 Protocolo de intenções entre Ministério da Saúde do Brasil e Ministério da Saúde e Ambiente da Argentina, sobre cooperação na área da Saúde relacionada a medicamentos, de 22.08.2005. Disponível em:< http://www2.mre. gov.br/dai/b argt 392 5561.htm>. Acesso em 14/04/16. 
minimizar os prejuízos em tais casos com ações que ocorram de forma aliada. O Acordo entre Brasil e Paraguai, de 21.05.2007, trata da cooperação entre os países "cuja finalidade é colaborar com o Ministério da Saúde Pública e BemEstar Social do Paraguai para o fortalecimento da vigilância epidemiológica no país, tendo o combate à dengue e o Regulamento Sanitário Internacional (2005) como eixos principais para a priorização das atividades" (http://www2.mre.gov. br/dai/b 218 5984.htm).

O Ajuste ao Acordo Sanitário relativo à Cooperação e Intercâmbio de Tecnologia de Saúde entre Brasil e Paraguai (http://www2.mre.gov.br/dai/b parg 154 3269.htm) mostra a preocupação desses países em controlar epidemias e agir no sentido da prevenção de doenças que afetam ambos os territórios, como consta no texto:

[...] intensificação das atividades de prevenção de situações de risco identificadas pelos dois países, como: malária, febre amarela, cólera, dengue, AIDS, raiva e outros males que afetem a saúde da população [...] fortalecimento dos sistemas de vigilância sanitária e epidemiológica em todos os níveis, em especial no controle de migrantes e problemas de saúde de fronteira.

A necessidade da união entre países visando fortalecer a saúde, especialmente nas fronteiras, apresenta-se no Ajuste Complementar ao Acordo para Permissão de Residência Estudo e Trabalho a Nacionais e Fronteiriços Brasileiros e Uruguaios para prestação de Serviços de Saúde (http://www2.mre.gov.br/dai/b urug 297. $\underline{\mathrm{htm}}$ ). Este acordo tem como objetivos principais consolidar soluções por meio de instrumentos jurídicos que facilitem o acesso dos cidadãos fronteiriços aos serviços de saúde, nos dois lados da fronteira e [...] amparar o intercâmbio que já existe na prestação de serviços de saúde humana na região fronteiriça. É fundamental que busquemos a simplificação da burocracia com vistas ao favorecimento desta relação entre os países. Desta forma, otimizamos a concretização de tais objetivos.

Entre Brasil e Uruguai, há também o Acordo de Cooperação Sanitária (http:// www2.mre.gov.br/dai/b urug 170 4027.htm), promulgado no ano de 1981. Este é mais um exemplo do reconhecimento da importância dos esforços coletivos entre países vizinhos para o controle de enfermidades que inevitavelmente cruzam suas fronteiras. Consta no acordo: fatores de natureza epidemiológica, no 
âmbito do país vizinho, podem produzir repercussões indesejáveis, além-fronteiras, comprometendo a saúde da população em áreas densamente povoadas. $\mathrm{O}$ acordo aqui citado refere-se às consequências da facilidade dos fluxos entre os países: o desenvolvimento dos meios de transporte e trânsito de pessoas e de bens, de um para outro país, proporciona maiores facilidades para o ingresso de vetores e de agentes patogênicos capazes de produzir situações de agravo à saúde coletiva.

A alarmante questão HIV/AIDS atinge a população mundial em sua totalidade, tendo transposto limites geográficos. No Brasil, os soropositivos têm direito a tratamento gratuito (http://www.aids.gov.br/). Neste aspecto, o Brasil tem cooperado com outros países da América Latina; é o caso do Projeto Assistência e tratamento a pessoas vivendo com HIV e AIDS na Colômbia (http://www2.mre. gov.br/dai/b colo 101 5622.htm), o qual define as incumbências de cada país, proporcionando conjuntamente as condições para atendimento e tratamento. Desde 1989, Brasil e Guiana têm um Protocolo de Intenções na área da Saúde (http://www2.mre.gov.br/dai/b guia 40 2599.htm), que define 0 atendimento de guianenses em hospitais brasileiros.

Com a Bolívia, o Brasil tem um projeto para o fortalecimento da vigilância sanitária, implementado em 2009 pelo ajuste complementar ao Acordo Básico de Cooperação Técnica, Científica e Tecnológica (http://www2.mre.gov.br/dai/b boli 261.htm).

Os laços internacionais em favor da saúde pública e consequentemente a efetivação do direito à saúde, realizados a partir desses instrumentos, possibilitam atender às necessidades das populações fronteiriças. Entretanto, não só estas porções populacionais são beneficiadas; cada país envolvido é favorecido como um todo.

\section{O CENÁRIO JURÍDICO-INSTITUCIONAL NA EUROPA}

Na Europa, além das declarações dos textos constitucionais, tratados, convenções, o direito à saúde parece ligar-se a um espaço político que deixa os Estados nacionais livres para fazerem escolhas, que muitas vezes se apresentam como excludentes. Obviamente, ninguém, em nível teórico, imagina-se negando o direito absoluto à saúde. Todavia, a ausência de políticas de integração conscientemente elaboradas torna a atuação difícil, perpetuando uma situação de exclusão e segregação social do estrangeiro, muitas vezes irregular. 
Este quadro não é novo. Na Europa, o desenvolvimento de uma estratégia de políticas comuns a todos os Estados membros no tema da imigração desabrocha nos dias atuais. O problema da imigração parece não interessar ao constituinte europeu dos anos 1957, diferente do que aconteceu em relação à livre circulação das pessoas e do mercado. O Tratado de Roma reconhecia entre os seus princípios fundamentais o direito à livre circulação das pessoas, no artigo 3, mas os condicionava ao desenvolvimento de uma atividade laboral e ao pertencimento a um dos estados da comunidade (Art. 48-66) ${ }^{28}$. A dimensão na qual se move o legislador comunitário é exclusivamente econômica. Somente com o Tratado di Maastricht (de 1992, Tratado da União Europeia que modifica os tratados institutivos da comunidade), a questão da imigração se torna objeto de atenção do legislador europeu. A mudança, na Europa, do cenário econômico e social, impõe uma nova reflexão a respeito da questão migratória dos cidadãos vindos de outros países. ${ }^{29}$

O Tratado de Maastricht foi, porém, importante por outro motivo, aparentemente não coligado com as políticas em matéria de imigração. Trata-se, na verdade, de um perfil que coloca as condições para a superação daquela visão excludente da cidadania entendida como aquela de pertencer. $\mathrm{O}$ tratado induz, de fato, significativamente a um conceito de cidadania europeia no novo capítulo do Tratado da Comunidade Europeia (art. 8 - 8E) relativo, justamente, à "cidadania da União"30. A cidadania europeia deve ser considerada como o primeiro passo concreto para a superação da ideia de soberania nacional e da dimensão e do significado atuais do direito de cidadania. O desalinhamento entre cidadania e nacionalidade seguramente é uma inovação de conceito e deixa transparecer a possibilidade de um direito dialogado e compartilhado que, superando a dimensão exclusiva, parece querer liberar-se da lógica amigo/inimigo.

28 O Tratado de Roma de 1957 institui a Comunidade Europeia. O tratado foi depois modificado com o Ato Único Europeu, que entrou em vigor em 1987. Este documento logo recebeu ulterior modificação com o Tratado de Maastricht.

29 A outra novidade que resguarda a imigração é a inserção no Tratado CE do art. 100 C (e do correlacionado 100 D), que confia à Comunidade o dever de determinar países terceiros aos quais o cidadão necessita de um visto para ingresso na União. U. Morcavallo, I diritti degli immigrati nell'Europa sopranazionale, in Diritto, Immigrazione e Cittadinanza, n. 2/2001, p. 22 ss.; C. Curti Gialdino, Schengen e il terzo pilastro: il controllo giurisdizionale secondo il Trattato di Amsterdam, in Rivista di Diritto Europeo, 1998, p. 54 ss.

30 O Tratado de Maastricht coloca em prática outro fragmento da integração. Isso, na verdade, fixa os critérios políticos e parâmetros econômicos para o ingresso na União. Entrou em vigor em $1^{\circ}$ de novembro de 1993 e é conhecido também como Tratado sobre a União Europeia (TUE). U. Morcavallo, I diritti degli immigrati nell'Europa sopranazionale, cit., p. 22 ss. 
O reconhecimento a cada cidadão da titularidade de direitos universais abre, mais do que tudo, um processo de identificação da cidadania com a "participação" da pessoa ao destino da comunidade em que vive. Assim, em discussão, estão todos os instrumentos da democracia participativa: direito de voto, direito de participar das eleições do país em que o cidadão reside, direito de petição, tutela diplomática e assim por diante, e são estas as coordenadas por meio das quais desenvolvemos a participação democrática ${ }^{31}$.

Apesar das abstratas declamações, a ligação entre imigração e soberania nunca foi interrompida, com a consequência de deixar a cargo dos Estados Singulares Membros a dupla gestão da população e do governo do território, segundo a tradicional lógica inclusão/exclusão que distingue cidadãos e estrangeiros e, entre estes, distingue ainda entre regulares e irregulares.

A situação não mudou com a aprovação do Tratado de Lisboa ${ }^{32}$. Isoladas análises mais específicas que investem na questão da "gestão" dos fluxos migratórios, é interessante levar em consideração como a dimensão social do problema da imigração na Europa foi influenciada pelo desenvolvimento de uma política de ampla e pensada, sobretudo, para melhorar a situação geral dos cidadãos extracomunitários "legalmente residentes" na União, seja sobre o local de trabalho, seja nas relações sociais. Se uma crítica é possível, está no fato de que na Europa as tutelas se diferenciam segundo a regularidade de permanência da pessoa imigrada.

A necessidade de um seguro aos imigrados extracomunitários "regulares" e aos seus descendentes ressurgiu em termos de conhecimento da língua, habitação, instrução, formação profissional, saúde, porém sempre acompanhada por um debate em que a questão da boa integração dos imigrantes tenha sido

31 PEPINO, L. Legalità e diritti di cittadinanza nella democrazia maggioritaria, Relazione al decimo congresso nazionale di Magistratura democratica, em Questione giustizia, 1993, p. 250.

32 "A versão consolidada provisória do Tratado que institui uma Constituição pela Europa", considera a matéria imigração como um dos elementos do "espaço de liberdade, segurança e justiça", previsto na parte III ("As políticas e o funcionamento da União"). Em particular, a política da imigração vem contemplada entre as políticas (e ações) internas, unicamente as políticas que resguardam os controles das fronteiras e do asilo (título III, sessão II do capítulo IV). A respeito da normativa pré-vigente, as disposições que dizem respeito à "política comum de imigração" (art. III- 168, par. 1) fazem emergir um maior interesse sobre a normativa vigente. São especificadas algumas prioridades, como as definidas pelo Conselho Europeu Extraordinário de Tampere (15-16 de outubro de 1999) como, por exemplo, a prevenção e o contraste da imigração clandestina em uma gestão mais eficaz dos fluxos migratórios, cfr., neste sentido: NASCIMBENE, B. Politica sull'immigrazione e progetto di Costituzione europea, in Studi Emigrazione/Migration Studies, XLI, n. 153, 2004, p. 71. 
tratada na perspectiva da adaptação destes últimos ao estilo de vida dos países que os abrigam, garantindo a preservação da própria identidade cultural. 0 discurso sobre a igualdade foi fundado sobre a reflexão de que a igualdade de direitos implica sempre paridade de deveres.

Teoricamente, então, se prestarmos atenção ao perfil de escolhas normativas feitas pelo legislador comunitário, não caberia nenhuma desaprovação, pois efetivamente parece mover-se na perspectiva de integração mesmo quando precisou adotar medidas para "deter" o fenômeno dos fluxos migratórios ${ }^{33}$. Concretamente, porém, a integração permaneceu presa a uma lógica econômica que em presença de qualificações insuficientes, interesses do mercado e das indústrias que ocupassem mão de obra a baixo custo, lacunas linguísticas, limitadas perspectivas de trabalho e carreira facilitariam condutas discriminatórias em dano ao imigrado extracomunitário em maior razão se irregular ${ }^{34}$. Neste caso, a possibilidade de ocupar mão de obra irregular a baixo custo abre a possibilidade do fenômeno de trabalho em condições análogas às de escravo.

Interessante observar que nenhum Estado da União ratificou a Convenção internacional sobre a proteção dos direitos de todos os trabalhadores imigrados e dos membros das suas famílias - ONU, 18 dezembro $1990^{35}$.

O paradoxo da inclusão/exclusão, na realidade dos fatos, depara-se com lógicas de um mercado que não observa o indivíduo e se distancia de qualquer possibilidade solidária e fraterna. O sentido da fraternidade que inclui desaparece nos meandros dos interesses de mercado que muitas vezes esquecem e ignoram as pessoas. A saúde, neste contexto, pode ser considerada como um tema indicativo de como a dimensão da inclusão, sempre proclamada, pode naufragar nas dificuldades econômicas ou mesmo nas questões normativas que enxergam o estrangeiro como "estranho" sem se colocar na perspectiva dialógica do outro. A dialética exclusão/inclusão, a prova dos fatos se encontra com a lógica de um mercado que não olha para a pessoa e se afasta da dimensão solidária.

33 O referimento é a recente diretiva sobre repatriados 2008/115.

34 Na verdade campanhas contra a xenofobia, contra o racismo e para favorecer a educação são periodicamente lançadas pela Comissão.

35 Assembleia Geral, Resolução 45/158 de 18 dezembro 1990. Não há dúvidas de que a falta de retificação da referida convenção, que constitui o quadro jurídico internacional mais extenso no âmbito da proteção dos direitos dos trabalhadores, parece remeter à causa de valores essenciais da UE. 
O senso de uma fraternidade que inclui desaparece entre os ramos de interesse do mercado que muito frequentemente esquece a pessoa, o cidadão. A saúde, neste contexto, pode ser considerada tema indicativo de como a dimensão inclusiva, sempre proclamada, pode naufragar com os icebergs de dificuldade econômica ou de medidas normativas que veem o estrangeiro como um "estranho" e não se propõe na perspectiva dialógica "do outro".

\section{CONSIDERAÇÕES FINAIS}

Neste artigo, procuramos focar a necessidade de efetivar o direito ao direito à saúde ultrapassando fronteiras, sem criar novas! Para isso, estudamos alguns acordos binacionais do Mercosul e entre países do Mercosul, bem como apresentamos alguns aspectos da realidade europeia. Com isso, identificamos que temos muito mais direitos do que efetivamente podemos realizar, mas vimos também que leis e legislações - as mais variadas - não nos faltam. Continuamos com algumas indagações: como o fenômeno da globalização reflete nos fundamentos do Estado-nação? Quais são as relações entre os poderes públicos e a globalização jurídica? É possível transportar justiça e democracia para além das fronteiras do Estado? Qual justiça estamos ultrapassando, se é que ultrapassamos? Qual democracia?

Ora, o questionamento sobre a possibilidade de uma justiça e de um direito global capazes de efetivar todos os direitos fundamentais - não podemos mais ser cidadãos pela metade, ou cidadãos servos ${ }^{36}$ - passa necessariamente pela forma como lidamos com os diferentes. Seguindo os pressupostos teóricos deste artigo, retomamos a fraternidade, que nos leva a ver o outro - inclusive e, sobretudo, o diferente, como um irmão, como um outro EU. Nesta sociedade cosmopolita, precisamos refletir sobre a situação da migração, fenômeno antigo, mas que, na contemporaneidade, assume um novo patamar de exclusão ${ }^{37}$.

A Constituição Federal Brasileira, assim como de vários Estados da União Europeia, ao dar tratamento igualitário aos cidadãos natos e estrangeiros residentes no país, assegurou a estes a possibilidade de acesso às políticas públicas existentes. A Lei brasileira 9.474/97, por sua vez, expressão do compromisso do 
Brasil com a causa humanitária do refúgio, chamou o país à efetivação destes direitos quando sinalizou para a implementação de políticas públicas para a integração dos refugiados e refugiadas.

A fraternidade se concretiza, quando transformamos a utopia em realidade. Foi exatamente esta aposta que fizeram os operadores do direito e da saúde na divisa entre Brasil e Uruguai em 2009, nas cidades Rivera (Uruguai) e Santana do Livramento (Brasil). Relatamos brevemente esta experiência para demonstrar que a fraternidade pode aproximar nações, resolver problemas, ultrapassar os limites de um direito positivista, buscar um direito achado na rua, construído a partir das necessidades de agrupamentos sociais cujas fronteiras podem ser um local de vida, de felicidade e de ousadia.

A história desta integração transfronteiriça pode ser demarcada no ano de 2006, quando foi criado o primeiro comitê binacional de saúde. Todo este processo tem como marco o Acuerdo de asistencia gineco-obstétrica de emergencia entre comisión de apoyo al hospital de Rivera, hospital santa casa de misericordia y secretaría de saúde de Livramento ${ }^{38}$. Este acordo foi estabelecido em função da greve de médicos em Santana do Livramento; a população ficou desassistida, e o hospital de referência obstétrica estava distante aproximadamente $150 \mathrm{~km}$. Então, o prefeito e o secretário municipal de saúde buscaram uma alternativa: um acordo, que permitiu a ruptura de várias fronteiras. Assinado em 07.11.2006, prevê a atenção às gestantes brasileiras usuárias do SUS e diz: "La paciente deberá presentar toda la documentación individual y aquella que pueda acreditar y aportar datos sobre controles prenatales, exámenes previos, así como cualquier otra documentación que facilite su correcta asistencia".

O que podemos observar é efetivamente um pacto estabelecido na solidariedade de ambos os lados, pois embora tenha existido uma contrapartida da Santa Casa de Santana do Livramento, o país vizinho auxiliou de modo significativo na redução da mortalidade infantil e da própria gestante, garantiu uma boa qualidade de atenção neste momento peculiar da vida da mulher.

Esta situação concreta evidenciou a possibilidade de solução conjunta de problemas das duas cidades, como acidentes de trânsito, combate ao mosquito da dengue, campanhas de prevenção da AIDS.

38 Livramento é o outro modo como o município de Santana do Livramento é habitualmente chamado/conhecido. 
Novas situações fronteiriças obrigam as autoridades brasileiras a fazer um ajuste complementar ao acordo para permissão de residência, estudo e trabalho a nacionais fronteiriços brasileiros e uruguaios para prestação de serviços de saúde. Este acordo é originariamente de 21.08.2002, e o ajuste foi publicado em 14.12.2009. No ajuste, encontramos a seguinte frase: "reafirmando o desejo de encontrar soluções comuns para o bem-estar e a saúde das populações dos dois países;" ou, ainda, "destacando a importância de consolidar soluções por meio de instrumentos jurídicos que facilitem o acesso dos cidadãos fronteiriços aos serviços de saúde, nos dois lados da fronteira". Estas indicações permitiram os avanços nas relações entre as fronteiras. Fundada no referido acordo, a Escola de Saúde Pública - Secretaria Estadual de Saúde - inicia, em março de 2010, o I Curso Binacional de Saúde Pública em Santana do Livramento. As vagas deste curso foram distribuídas igualmente entre os dois países e destinavam-se aos trabalhadores de fronteiras.

Eligio Resta ${ }^{39}$ constantemente aborda a possibilidade de mudar a humanidade da humanidade. Ele tem razão, pois esta situação, ainda que pouco frequente, existe, e é o que podemos observar com a situação que vem ocorrendo na fronteira Brasil - Uruguai.

Em 15.10.2009, uma nova situação desafia os gestores da saúde de Santana do Livramento: o fechamento do único hospital da cidade - a Santa Casa. Naquele momento, a Prefeitura decide decretar "emergência na área de saúde pública". As tentativas de reabertura só se efetivaram em abril de 2010. Mais uma vez, foram reforçados os acordos já existentes e se estabeleceu um novo convênio entre os hospitais das duas cidades. No período em que a Santa Casa esteve fechada, por determinação do Sindicato Médico do Rio Grande do Sul, nasceram no Uruguai 181 crianças. Os registros de nascimento destes brasileiros nascidos no Uruguai foram realizados no Consulado Brasileiro em Rivera.

Ainda sobre essa questão de Rivera, é válido destacar que, com relação à política de cooperação, integração e desenvolvimento da fronteira do Brasil com a República Oriental do Uruguai, em 14 de junho de 2004, foi promulgado o Acordo para Permissão de Ingresso, Residência, Estudo e Trabalho, Previdência

39 RESTA, Eligio. II diritto fraterno. Editori Laterza: Roma/Bari, 2009. 
Novos Estudos Jurídicos

Social e Concessão de Documento Especial de Fronteiriço a nacionais fronteiriços brasileiros e uruguaios, celebrado em 21 de agosto de 2002 em Montevidéu, Uruguai (disponível em http://www2.mre.gov.br/dai/b_urug_255_5003.htm).

Interessa-nos, especialmente, os artigos I e VI, que tratam sobre a permissão de residência, estudo e trabalho aos nacionais de uma das partes envolvidas residentes nas localidades de fronteira com o objetivo de fortalecer ainda mais a dimensão social de integração entre os países. Notemos, pois, que esse acordo ultrapassa as fronteiras de cunho comercial e econômico.

Sobre a permissão de residência, estudo e trabalho, podemos dizer que os nacionais de um dos dois países, residentes nas localidades fronteiriças listadas no anexo de "Localidades Vinculadas", terão permissão para: a) residência na localidade vizinha, situada no território da outra parte, a qual fica vinculada na forma deste acordo; b) exercício de trabalho, ofício ou profissão, com os efeitos advindos das obrigações e direitos previdenciários deles decorrentes; c) frequência a estabelecimentos de ensino públicos ou privados. $O$ artigo I faz menção à condição de fronteiriço, em que aparece, inicialmente, a possibilidade de autorização por cinco (05) anos, prorrogáveis por igual prazo. Ao final desse prazo, o cidadão poderá ter concedida essa condição por prazo indeterminado que valerá, em qualquer caso, exclusivamente nos limites da localidade para a qual foi concedida.

Também, sobre a situação dos migrantes, os exemplos na Europa são numerosos e diferem segundo o país. Na Itália, de modo particular, uma lei no quadro de um pacote de provimentos relativos à segurança elegeu a "imigração clandestina" como uma contravenção penal ${ }^{40}$. Os médicos que tivessem conhecimento, em função de sua atividade, de pessoas irregulares presentes no território deveriam denunciar à autoridade judiciária a presença destas pessoas (art. 361 e 362 Código Penal Italiano). E se pensarmos que, para o médico, a obrigação de denunciar a autoridade judiciária supera o limite do segredo profissional, qual, neste contexto, seria o espaço para a tutela do direito à saúde e para o significado que isso atribui ao Art. 32 da Constituição da Itália para fins de tutela da pessoa?

40 A referência é ao art. 45 do Tratado de Segurança C2180 aprovado pelo Senado e não pela Câmara dos Deputados. A norma se fundiu no dlg. em 15 de julho 2009/94, "pacote de segurança". 
A doutrina prontamente evidenciou o risco da criação de um "sistema paralelo de saúde", subtraído de qualquer forma de controle e que marginalizasse ainda mais os pobres e os imigrantes, sem considerar os efeitos negativos que um sistema deste tipo pudesse determinar a saúde coletiva.

No novo texto do decreto lei de 23 de junho de 2001, n. 89, convertido em lei em 2 de agosto de 2011, n. 129 a previsão não aparece mais. O problema da imigração, porém, permanece com a falta de uma política sanitária que leve em conta a relevância que a saúde assume no papel da inclusão.

A sociedade cosmopolita está em permanente transformação: a fraternidade, como pressuposto, acelera este processo no sentido da efetivação de direitos escritos e pouco efetivados; ela também permite uma ruptura de fronteiras na vida cosmopolítica. Por fim, as fronteiras precisam e podem ser lugares de apropriação.

\section{REFERÊNCIAS DAS FONTES CITADAS}

André-Jean ARNAUD et al. Dicionário enciclopédico de teoria e sociologia do direito. Tradução de Patrice Charles, F.X Willaume. Rio de Janeiro: Renovar, 1999.

BAUMAN, Zygmunt. La società sotto assedio. Tradução de Sergio Minucci. Editori laterza, Roma- Bari, 2005.

CAPELA, Juan Ramón. Os cidadãos servos. Porto Alegre: Sergio Antonio Fabris Editor, 1998. CASSESE, Sabino. Il diritto Globale. Giustizia e democrazia oltre lo satto. Enaudi, Torino, 2009. DALLARI, Sueli Gandolfi e VIDAL, Serrano Nunes Junior. Direito Sanitário. São Paulo: Editora Verbatim, 2010.

FERRAJOLI, Luigi. Principia iuris. Teoria del diritto e della democaracia.Teoria della democrazia. v. 1. Editori Laterza: Roma- Bari, 2007.

FISTETTI, R. Finelli; LUCIANI, F. R.; VITTORIO, P. Globalizzaione e diritti futuri. Roma: Manifestolibri, 2004.

LEONARDI, Victor Paes de Barros. Violência e direitos humanos nas fronteiras do Brasil. Coleção "Violência e Direitos Humanos", I Brasília: paralelo 15, 2007.

LUHMANN, Niklas e DE GIORGI, Raffaele. Teoria della Società. Milano: Franco Angeli, 1996. KOHAN, Néstor. O Império de Hardt \& Negri: para além de modas, 'ondas' e furores. En 
publicacion: Filosofia Política Contemporãnea: Controvérsias sobre Civilização, Império e Cidadania. Atilio A. Boron, 1a ed. - Buenos Aires: Consejo Latinoamericano de Ciencias Sociales - CLACSO; São Paulo: Departamento de Ciência Política. Faculdade de Filosofia, Letras e Ciências Humanas. Universidade de São Paulo, 2006.

NASCIMBENE, B. Politica sull'immigrazione e progetto di Costituzione europea. In: Studi Emigrazione/Migration Studies, XLI, n. 153, 2004.

OLIVEN, Ruben. Fronteiras; arte e pensamento na época do multiculturalismo. Fernando Schuler e Marília de Araujo Barcellos (orgs). Porto Alegre: Sulina, 2006.

PEPINO, L. Legalità e diritti di cittadinanza nella democrazia maggioritaria, Relazione al decimo congresso nazionale di Magistratura democrática. In: Questione giustizia, 1993.

RESTA, Eligio. In: Globalizzazione e diritti futuri. A cura di R. Finelli, F. Fistetti, F.R. Recchia Luciani, P. Di Vittorio. Ministero dell'Istruzione. Roma: Università e Ricerca scientifica, 2004.

RESTA, Eligio. Diritto vivente. Eiditori Laterza, Bari, 2008.

RESTA, Eligio. Il diritto fraterno. Editori Laterza: Roma/Bari, 2009.

RICOVERI, Giovana (org). Capitalismo Natura e Socialismo. Milano: Jaca Book, 2006.

RODOTÀ, Stefano. La vita e le regole. Tra diritto e non diritto. Feltrineli, Milano, 2006.

RODRIGUES, Francilene. Migração transfronteiriça na Venezuela. Estud. 2006, vol.20, n.57, pp. 197-207. Disponível em: <http://www.scielo.br/scielo.php?pid=S010340142006000200015\& script=sci arttext $>$. Acesso em 14 de abril de 2016.

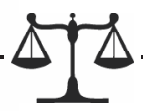

Recebido em: abril/2017

Aprovado em: março/2018 